
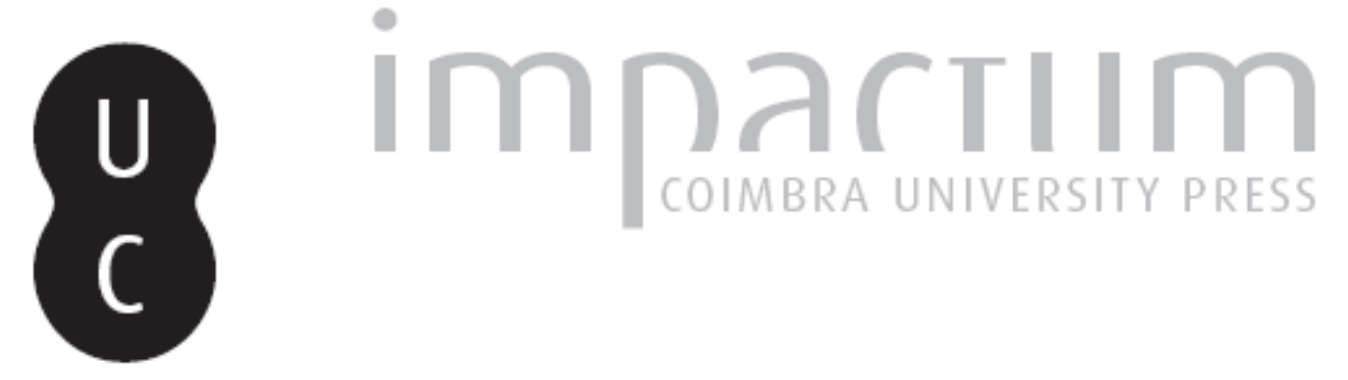

\title{
[Recensão a] Trepte, Peter - Regulating Procurement: understanding the ends and means of public procurement regulation
}
Autor(es):
Almeida, Teresa

Publicado por: Faculdade de Direito da Universidade de Coimbra

URL persistente:

URI:http://hdl.handle.net/10316.2/24736

DOI:

http://dx.doi.org/10.14195/0870-4260_52_8

Accessed : $\quad$ 26-Apr-2023 07:28:26

A navegação consulta e descarregamento dos títulos inseridos nas Bibliotecas Digitais UC Digitalis, UC Pombalina e UC Impactum, pressupõem a aceitação plena e sem reservas dos Termos e Condições de Uso destas Bibliotecas Digitais, disponíveis em https://digitalis.uc.pt/pt-pt/termos.

Conforme exposto nos referidos Termos e Condições de Uso, o descarregamento de títulos de acesso restrito requer uma licença válida de autorização devendo o utilizador aceder ao(s) documento(s) a partir de um endereço de IP da instituição detentora da supramencionada licença.

Ao utilizador é apenas permitido o descarregamento para uso pessoal, pelo que o emprego do(s) título(s) descarregado(s) para outro fim, designadamente comercial, carece de autorização do respetivo autor ou editor da obra.

Na medida em que todas as obras da UC Digitalis se encontram protegidas pelo Código do Direito de Autor e Direitos Conexos e demais legislação aplicável, toda a cópia, parcial ou total, deste documento, nos casos em que é legalmente admitida, deverá conter ou fazer-se acompanhar por este aviso.

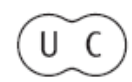




\section{UNIVERSIDADE DE COIMBRA \\ FACULDADE DE DIREITO}

BOLETIII DE CÊACCLS ECONÓNCACAS

VOLUME LII

$\begin{array}{llll}2 & 0 & 0 & 9\end{array}$

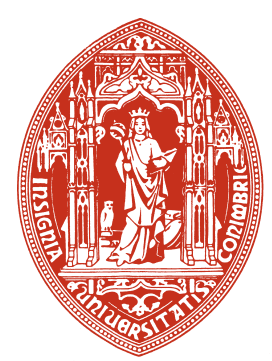

COIMBRA 


\section{Recensões}

Trepte, Peter, Regulating Procurement, understanding the ends and means of public procurement regulation, Nova York, Oxford University Press, 2004, 395 pp., ISBN 0-19826775-4

Esta é uma obra que procura uma perspectiva prática para uma temática que dificilmente o é: os princípios económicos que subjazem a alguns dos objectivos das diferentes legislações sobre mercados públicos.

Peter Trepte, especialista na matéria, quer enquanto advogado, quer enquanto consultor para várias organizações internacionais, partindo da verificação empírica da variedade de abordagens possíveis para a regulamentação das compras públicas, procura em todas elas um sentido e, talvez mais importante, tenta uma forma de compatibilização entre essas diversas abordagens, ancoradas em objectivos também eles diversos.

A obra está dividida em duas grandes partes, e cada um delas em capítulos e sub-capítulos. A primeira parte trata da lógica da regulação nesta área; a segunda dá alguns exemplos de sistemas concretos, quer nacionais, quer internacionais, que servem de ilustração para o que se desenvolveu anteriormente.

Salientaremos a primeira parte, na medida em que é onde encontramos o verdadeiro "coração" da obra - procurar os fundamentos dos objectivos que encontramos no legislador e tentar a sua compatibilização em termos de um quadro normativo coerente.

$\mathrm{O}$ autor, confrontado com a enorme variedade de textos, mais jurídicos ou mais económicos, acerca das compras públicas, e dada a importância que o tema reveste, quer nos países mais 
desenvolvidos, quer (e talvez especialmente) naqueles em vias de desenvolvimento, procura nesta obra responder a duas perguntas básicas relativas a esta problemática - o porquê da necessidade de regulação dos mercados públicos e quais os diversos objectivos que essa regulação pode cumprir.

Como o próprio salienta, para tal será necessária uma análise, se bem que jurídica (nomeadamente comparatística), fundamentalmente económica.

O autor inicia com uma pequena introdução, na qual explicita os objectivos da investigação e enquadra economicamente o tema: entrando na questão do relacionamento do estado com o mercado, realça a necessidade da provisão de bens públicos; analisando as várias possibilidades dessa provisão, identifica nessa necessidade uma das fontes da crescente importância dos mercados públicos, resultado das recentes tendências de minimização das máquinas estaduais, com um cada vez maior recurso ao outsourcing a privados.

Tendo em consideração as várias realidades existentes, alerta ainda neste primeiro capítulo para as várias abordagens que o tema pode sofrer, dependentes da realidade jurídico-organizativa e da própria história da intervenção estatal (realça, a este aspecto, a diferença fundamental entre os países de influência anglo-saxónica com um estado tendencialmente reduzido e os países da Europa continental, nomeadamente a França - se nuns a regulação que se quer operar é dos mercados públicos, isto é, nos mercados onde um dos operadores é uma entidade pública, já nos outros, onde o direito público está mais autonomizado, se opta por uma abordagem mais contratualista, procurando determinar o modus específico deste tipo de contratos).

Para além das diferenças entre ordenamentos internos, são ainda referidas as diferenças entre ordenamentos puramente internos e ordenamentos internacionais, bem como as possíveis incompatibilidades entre objectivos nacionais e internacionais. A este respeito o autor refere o enquadramento dado ao tema na União Europeia, bem como a nível da Organização Mundial de Comércio (sistemas que, vai utilizar na segunda parte enquanto exemplos de regulação internacional); salienta ainda a importância do modelo legislativo UNCITRAL que, procurando servir de enquadramento 
para as diversas legislações nacionais, visa diminuir os obstáculos ao comércio internacional eventualmente criados por legislações mais proteccionistas.

No último ponto deste primeiro capítulo o autor explicita a sua tese - não há um modelo adequado para a regulação destes mercados: tudo dependerá, para além é claro das diferenças intrínsecas de realidade para realidade, dos objectivos a prosseguir. Daí que, do sub-título escolhido, "understanding the ends and means", seja a primeira parte a mais relevante.

Os objectivos que podem ser prosseguidos através da regulação das compras públicas são vários. $\mathrm{O}$ autor divide-os em três grandes grupos:

1) objectivos de eficiência económica;

2) objectivos de agenda social ou política dos governos;

3) objectivos de comércio internacional.

Trata cada um destes grupos nos capítulos seguintes da primeira parte.

No segundo capítulo aborda a problemática da primeira perspectiva - os governos podem regular as compras públicas "apenas" por objectivos de eficiente alocação de recursos. Esta será uma visão mais estreita, diz-se, mas é uma perspectiva importante para compreendermos as demais. É que dizer que é necessária uma qualquer regulação para atingir a eficiência implica assumir que os mercados públicos não são, por si, eficientes. E a verdade é que a maioria dos autores o reconhece, dos mais fervorosos defensores da eficiência dos mercados em geral aos defensores de uma necessária intervenção estatal baseada precisamente nas falhas de mercado.

O autor tenta, então, dar uma resposta à questão dos motivos dessa ineficiência destes mercados. Opta por enunciar as características dos mercados de concorrência para, comparando, demonstrar as diferenças.

A primeira prende-se com a chamada "teoria da agência" - na medida em que o estado é um comprador especial, perdem-se características da concorrência. O facto é que quem compra é um agente ao serviço do principal, isto é, de alguém eleito democraticamente. A respeito da agência são resumidas, mais à frente, as 
características mais relevantes deste tipo de relação. Destaca entre elas a questão das assimetrias de informação, quer elas se revelem em termos de informação sobre preços ou sobre diferenciação de produtos, quer em termos de diferente grau da mesma entre principal e agente, quer mesmo no que respeita ao relacionamento entre agente e fornecedor.

O autor relembra as consequências desta relação: o agente, que é quem tem o poder de facto e os conhecimentos do mercados, tem interesses que serão em alguns pontos divergentes dos do principal, o que origina compras nem sempre orientadas pelo princípio da eficiência económica.

Em primeiro lugar devido a problemas ligados à corrupção dos agentes. A este respeito o autor evidencia as principais características deste tipo de comportamento, bem como as maiores dificuldades que se opõem às medidas de combate.

Mas igualmente devido a, por várias ordens de razões, o principal não conseguir fazer com que os seus agentes actuem nas compras públicas segundo o princípio da maximização de resultados, o que provoca as referidas ineficiências. A este respeito aborda a problemática da eficiência em geral das organizações públicas. Lançando mão de alguns estudos na matéria, defende que, não se podendo afirmar peremptoriamente a menor eficiência destas relativamente às privadas, sempre se pode concluir pela tendencial menor eficiência destas em ambientes competitivos (por oposição a mercados de monopólios naturais, por exemplo). Ainda em matéria de comportamento de entidades públicas, uma característica sobressai: o facto de serem tendencialmente viradas para si mesmas, tendo dificuldade em orientar a sua actividade pelo mercado. Este facto aporta algumas exigências de intervenção, nomeadamente nos mercados públicos, onde se torna necessário introduzir legalmente exigências de concorrência e constestabilidade.

Em terceiro lugar, uma outra consequência desta relação de agência. $O$ facto de o agente ter informações que o principal desconhece faz com que ele possa orientar a sua conduta de um modo diverso dos interesses do principal. Uma dessas possibilidades prende-se com a influência de certos grupos de interesses que, ao fim de algum tempo, desenvolvem um relacionamento com o agente 
de forma a permitir-lhes orientar as suas decisões no sentido mais favorável (embora, note-se, tal influência seja muitas vezes exercida sobre o próprio principal).

Para além da relação de agência, são ainda referidas outras causas da necessidade de regulação, nomeadamente uma deficiente contestabilidade nestes mercados. Isto porque, para além dos problemas de informação já referidos, comprador ou vendedor têm posição dominante no mesmo (muito comum nestes mercados, especialmente em caso de compras dos chamados "bens públicos", normalmente produzidos por um reduzido número de empresas privadas, o que aumenta o poder do vendedor; bem como no caso das utilities, onde se denota o oposto, isto é, um enorme peso das compras públicas no mercado total, aumentando muito o peso do comprador). Essa posição dominante leva uns e outros a poder tem influência sobre os preços; porque vendedores beneficiam de certos efeitos como o moral hazard ou a adverse selection de forma a não revelar os seus verdadeiros custo e conseguir preços artificialmente altos; ou porque os produtos não são homogéneos ou há restrições à entrada nos mercados.

O autor justifica desta forma uma parte de toda a regulação nestes mercados - para suprir deficiências dos mesmos, que fazem com que estes não funcionem de forma eficiente. Enquadram-se nestes objectivos as normas tendentes a introduzir transparência nos mercados; as que obrigam o agente a definir inicialmente os parâmetros segundos os quais vai orientar o seu comportamento e a sua decisão; as que garantem o máximo número possível de ofertantes nos mercados, bem como as que restringem a capacidade de, através de especificações técnicas dos produtos, se afastem determinados concorrentes; as que definem os tipos de concursos admissíveis e as circunstâncias da sua admissibilidade; as que definem os tipos contratuais a utilizar em cada caso, nomeadamente no que se refere às formas de pagamento possíveis. Todas elas no sentido de assegurar, por um lado, a possibilidade de controlo por parte do principal do comportamento dos agentes, e por outro, a efectiva concorrência no mercado, garantindo que os potenciais fornecedores tenham estímulos para revelar os seus verdadeiros custos. 
Há, no entanto, algumas opções legislativas que carecem ainda de explicações. É o caso de todas as que limitam, para determinados casos, a aplicação das exigências de máxima concorrência. Também nesta matéria é feita uma abordagem económica - estas opções fazem sentido na lógica da máxima eficiência referida anteriormente. Para demonstrar esta conclusão o autor lança mão da teoria dos custos de transacção.

De facto, todas as normas tendentes a assegurar a plena publicidade e transparência dos concursos, a máxima participação possível nos mesmos ou a recolha do máximo de informações possível dos concorrentes acarretam custos, quer para o adjudicante, quer para as empresas concorrentes. Ora a verdade é que estes não são despiciendos. Faz sentido, então, limitar essas exigências sempre que as vantagens que delas resultam sejam inferiores aos custos que implicam.

É o caso das provisões que admitem concursos restritos ou limitados, sempre que, pela dimensão da compra ou pelo número de ofertantes no mercado, não se justifique o concurso público.

Por outro lado, é igualmente necessário um menor nível de exigência sempre que se entenda fomentar a participação nos mercados públicos de empresas de pequena ou média dimensão que não teriam estrutura económica e técnica para responder satisfatoriamente a todos os requisitos dos concursos públicos.

Justificam-se também pelos custos de transacção as centrais de compras dos estados, no sentido de minimização de custos por compra efectuada, bem como os chamados "acordos-quadro", nos quais é permitido o estabelecimento de condições determinadas que valham para compras futuras por parte da entidade adjudicante ao concorrente vencedor.

No terceiro capítulo da primeira parte o autor analisa uma outra linha de motivação da regulação neste área - a utilização dos contratos públicos como instrumentos ao serviço de outras políticas governamentais. O que está em causa, salienta, é, mais do que garantir uma eficiente alocação de recursos numa linha de primeiro óptimo de Pareto, promover uma determinada orientação dessa afectação, privilegiando determinados aspectos considerados funda- 
mentais pelo legislador. Esses aspectos podem ser de ordem económica, social ou mesmo ambiental, tendo como denominador comum uma apreciação não apenas quantitativa mas já igualmente qualitativa relativamente ao modo como os recursos são utilizados na economia em causa - daí o título "The Government as a Body Politic".

Como é referido, este tipo de motivações depende em larga medida do grau de intervencionismo do estado em geral, admitindo-se que serão maiores naqueles em que se tente mais activamente redefinir a eficiência na alocação propiciada pelos mercados em geral na linha da conhecida "economia do bem-estar".

Não se pense, todavia, que tal escolha não compreende custos: como é salientado logo de início, a prossecução de políticas secundárias implicará sempre algum prejuízo em termos de eficiência económica pura. A questão está, então, numa avaliação custo/benefício de todas as eventuais medidas a tomar.

O autor trata esta problemática começando por descrever as práticas mais comuns em termos de políticas secundárias nos diversos países, passando depois para as implicações que estas têm na eventual violação do princípio da não discriminação, para terminar com alguns exemplos de normativos legais neste sentido. A lógica mantém-se inalterada: explicar as motivações para nelas enquadrar requisitos comuns às diversas legislações nacionais e internacionais.

Relativamente ao primeiro ponto, tenta uma classificação algo inovadora dos tipos de políticas secundárias: políticas estratégicas, proteccionistas e pró-activas.

Quanto às primeiras, liga-as ao pensamento de raiz Keynesiana, referindo-se a todas as medidas que tentam, através dos mercados públicos, influenciar positivamente as economias nacionais. Isto pode ser feito através de particular atenção a determinados sectores da mesma, porventura o caso mais comum, mas igualmente através de especificações técnicas e funcionais dos produtos exigidas nos concursos (programadas de forma a fomentar, por exemplo, a investigação e desenvolvimento) ou da chamada tied aid, muito utilizada pelos países desenvolvidos nos seus programas de ajuda ao desenvolvimento. Realça ao longo de toda a exposição a ténue fronteira que se estabelece entre este tipo de objectivos e a discrimi- 
nação de concorrentes em função da nacionalidade, proibida por todos os normativos internacionais nesta matéria, nomeadamente a legislação da União Europeia e o Acordo em sede de Organização Mundial de Comércio.

As políticas proteccionistas são divididas entre as que pretendem promover a indústria nacional e as que a pretendem proteger de concorrência internacional. Em ambos os casos a probabilidade de violação do princípio da não discriminação é altíssima. Neste ponto saliente-se a abordagem feita relativamente ao problema de articulação, em sede de legislação europeia, entre normas relativas às ajudas de estado e regulação de mercados públicos. O autor apresenta, nesta matéria, uma proposta de solução que parece conseguir conjugar os objectivos gerais do ordenamento comunitário.

A novidade parece estar na categoria de medidas "pró-activas". Na realidade, porém, não se trata de nada de novo - apenas se classificam separadamente todas as práticas dos estados que, "procuram ir além dos objectivos tradicionais da regulação dos mercados públicos numa tentativa de realizar, de forma activa, objectivos sociais mais amplos" (tradução nossa). Estamos, é claro, a falar de todas as medidas com objectivos de garantias laborais dos trabalhadores, igualdade no acesso ao trabalho, condições sociais, direitos humanos, protecção do ambiente, etc, objectivos esses que exigem medidas que imponham obrigações positivas aos concorrentes, e não apenas obrigações de non facere.

Seguindo a metodologia anunciada, o autor trata seguidamente as possíveis medidas de concretização dos objectivos descritos. Na sua opinião, haverá na maioria dos casos uma necessidade de adequação dos quadros legislativos pensados em função da eficiência pura das compras públicas de modo a prever possibilidades de políticas secundárias. Exemplifica essa adequação, acompanhando com casos jurisprudenciais, no que diz respeito a obrigações contratuais, selecção e qualificação de candidatos, especificações técnicas e critérios de adjudicação.

Não são, no entanto, apenas os estados nacionais que, nos nossos dias, têm políticas de compras públicas próprias. A verdade é 
que, devido ao desenvolvimento do comércio à escala mundial, cada vez há mais objectivos verdadeiramente internacionais nesta matéria. É essa problemática que o autor trata no quarto capítulo desta obra - "Government as International Actor".

Tal como no primeiro capítulo, o autor começa por descrever os princípios económicos que estão na base da defesa do livre-cambismo, nomeadamente a teoria das vantagens comparativas. Realça a importância da eficiência na produção, potenciada (e potenciadora) por economias de escala, por forma a permitir ganhos com a especialização e comércio internacional. Refere seguidamente as teorias que defendem o equilíbrio geral dos mercados (também) a nível internacional, não esquecendo os seus pressupostos - a existência de mercados de concorrência perfeita. Ao longo da exposição, e à medida que refere as características desses mercados, aproveita para enunciar algumas das circunstancias que afastam os mercados actuais dessa realidade, como sejam os mercados dos bens públicos, a desigualdade na dotação de factores que encontramos entre países, as ditas externalidades, a diferenciação de produtos e os problemas de informação. $O$ autor reserva ainda algumas páginas para a teoria da vantagem competitiva de Porter, uma tentativa de explicar os factores de vantagem de um país, para além da dotação de factores de produção.

De novo como no primeiro capítulo, o autor adverte o leitor para a possibilidade de o legislador ter outros objectivos que não apenas a eficiência económica, agora em termos de comércio internacional, os quais justificam barreiras ao comércio. Estas podem ir de restrições quantitativas a especificações técnicas, passando, obviamente pelas conhecidas preferências em termos de preço. São as barreiras "governamentais". Há, todavia, igualmente barreiras "privadas" ao comércio internacional como sejam os subsídios estatais ou o "dumping", também abordados.

Finalmente é tratado o tema dos vários modos de regulação possível. Neste ponto são salientadas duas realidades ao nível internacional: a legislação em sede de Organização Mundial de Comércio e a legislação Europeia sobre contratação pública. $\mathrm{O}$ autor dá, a este respeito, um tratamento sumário, mais preocupado em salientar 
as diferenças que encontramos quando os comparamos com ordenamentos puramente nacionais e os potenciais problemas que dessa situação podem advir. Reflecte ainda sobre as vantagens e desvantagens para os diversos países da adesão a este tipo de ordenamentos, para concluir que, tal como na ordem nacional, também ao nível internacional podem existir objectivos conflituantes, sendo de importância vital que o legislador tenha consciência deles, de forma a não comprometer a própria coerência do sistema.

Aliando a perspectiva teórica, nomeadamente em termos análise económica, à perspectiva empírica relativa às diferentes abordagens e possibilidades jurídicas, esta obra fornece aos leitores uma visão simultaneamente abrangente e detalhada sobre o rationale económico por trás das escolhas jurídico-políticas. Será uma obra de referência para economistas, mas igualmente para não economistas, nomeadamente juristas, que trabalhem na área dos contratos públicos e queiram entender as bases económicas fundamentais dos diversos sistemas normativos vigentes e das diferentes opções do legislador.

Teresa Almeida Assistente da Faculdade de Direito da Universidade de Coimbra 